\title{
Situación actual de la hepatitis B en Chile
}

\author{
Ana Pereira $\mathbf{S}^{1}$, María Teresa Valenzuela $\mathbf{B}^{2}$, Judith Mora ${ }^{3 a}$, \\ Lilian Vera ${ }^{3 b}$. \\ Present situation of hepatitis $B$ \\ in Chile
}

Background: Hepatitis B virus infection generates carriers and $8 \%$ will evolve to a chronic phase. Aim: To perform a compilation of studies on hepatitis B in Chile and other sources of information to estimate the impact of this disease in our country. Material and methods: Published and unpublished evidence about the infection, in the general population and risk groups in our country, was compiled and reviewed critically. Informal interviews to experts, revision of the mandatory notification book of the Ministry of Health and collection of data from laboratories that study hepatitis B virus, were also carried out. Results: The seroprevalence of chronic carriers in blood donors is nearly $0.3 \%$. Among risk groups such as health care personnel, the figure is $0.7 \%$, among homosexuals $29 \%$, among HIV positive patients $30 \%$, among sexual workers $2 \%$ and among children with chronic hemodialysis, 9\%. Prevalence rate according to notified cases in 2004 was $1.8 \times 100,000$ habitants. Detection of viral hepatitis B surface antigen in laboratories occurs in $0.2 \%$ of donors and $1.3 \%$ of non donors. Conclusions: The seroprevalence of hepatitis B virus, the lack of notification, and the introduction of hepatitis B vaccine to our Regular Program of Immunizations, are arguments to develop in Chile a hepatitis B and C surveillance system (Rev Méd Chile 2008; 136: 725-32).

(Key w ords: Hepatitis B; Hepatitis B virus surface antigen P31c; HIV)

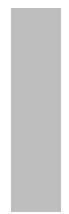

L a infección por el virus de la hepatitis $\mathrm{B}$, a pesar de no ser de alta prevalencia en Chile, genera portación crónica. Se estima que $8 \%$ de los

Correspondencia a: Dra. Ana Pereira Scalabrino. Independencia 939, Escuela de Salud Pública, Departamento de Epidemiología. Santiago de Chile. Teléfonos: (562) 9786142; (562) 9786546; (562) 9786823. Fax: (562) 7377121.

E mail: apereira@med.uchile.cl

aMédico Veterinario

${ }^{\mathrm{b}}$ Tecnólogo Médico
Recibido el 6 de agosto, 2007. Aceptado el 28 de enero, 2008.

${ }^{1}$ División de Epidemiología, Escuela de Salud Pública, Facultad de Medicina, Universidad de Chile. ${ }^{2}$ Departamento Salud Pública y Epidemiología, Facultad de Medicina, Universidad de los Andes. ${ }^{3}$ Subdepartamento de Virología, Instituto de Salud Pública de Chile.

portadores crónicos presentarán las fases crónicas de la enfermedad, como la hepatitis crónica o peor aún el hepatocarcinoma ${ }^{1}$. La prevalencia de infección: aguda, crónica y portación del virus de hepatitis B (VHB) fue altamente estudiada en Chile durante la década de 1980-892-12. Este interés fue declinando debido a la detección y reconocimiento de otros virus hepáticos ${ }^{13}$.

A nivel mundial, 50.000 personas al año mueren de hepatitis aguda por VHB y 450.000 por cirrosis hepática ${ }^{14}$. El $75 \%$ de la población mun- 
dial vive en zonas de alta prevalencia de infección, mayor a $8 \%$, que corresponde al sudeste asiático, China y África subsahariana ${ }^{15}$. En países del primer mundo, la infección crónica es menor de 1\%, en la región de las Américas el país con mayor infección crónica es República Dominicana: $21,4 \%$ y el comportamiento de Chile es como un país de baja endemia, menor a $1 \% 16,17$.

El propósito de esta publicación es efectuar una compilación de resultados de estudios sobre hepatitis B realizados en Chile y estimar la morbilidad que produce esta enfermedad en nuestro país, en base a esta información.

\section{MATERIAL Y MÉTODO}

Fuentes de información:

1. Recopilación de la evidencia publicada en el país y revisión crítica de la literatura encontrada para determinar la magnitud de la infección por el virus en: población general, donantes de sangre y en grupos de riesgo. Los grupos de riesgo a considerar fueron: personal de salud, homosexuales, pacientes infectados por VIH, hemodializados crónicos y trabajadores sexuales. Las fuentes de información para búsqueda de la literatura fueron Medline, Lilacs y Scielo. También se realizó búsqueda manual, se trabajó con la información de la Encuesta Nacional de Salud y literatura gris (no publicada).

2. Entrevista semi-estructurada a seis expertos realizada por los propios autores. Incluyó preguntas cerradas acerca de la magnitud de la infección, de la evolución de los casos infectados, los enfermos, sus contactos, manejo terapéutico de los casos y notificación de ellos. Además incorporó la opción de discusión de estos temas de forma abierta, donde ellos podían entregar aportes a esta área.

3. Evaluación de la concordancia entre lo notificado y publicado. La información sobre los casos notificados fue obtenida a través del Ministerio de Salud mediante los anuarios de Enfermedades de Notificación Obligatoria (ENO), Departamento de Estadísticas.

4. Recopilación de los datos obtenidos desde los laboratorios del país que realizan detección del antígeno de superficie del vinus hepatitis B (HB-
sAg), registrados en el Instituto de Salud Pública, a través del Programa de Control de Calidad Extema (PCCE) de esa Institución. Los datos registrados en estos laboratorios fueron informados al Laboratonio de Referencia, a través de una encuesta, lo que permitió conocer el número de muestras positivas a antígeno de superficie del virus hepatitis B (HBsAg), durante los últimos años (1999-2004).

Mediante los datos obtenidos se estimarán los casos de evolución crónica que requerirán ser tratados en Chile.

Definiciones ${ }^{14,18}$ :

Seroprevalencia de infección aguda: se define como la presencia de anticuerpos IgM anti core (IgM anti-HBc) y antígeno de superficie de virus hepatitis B (HBsAg).

Seroprevalencia de infección crónica: se define como la presencia de anticuerpos IgG anti core (IgG anti-HBc) y HBsAg.

Replicación viral: se define como tal la presencia de ADN del virus de hepatitis B (VHB-ADN) y antígeno e de hepatitis B (HBeAg).

Portación: se define por la presencia de HBsAg por más de 6 meses de ocurrida la infección, se diferencia de la hepatitis crónica por la ausencia de síntomas ${ }^{15}$. En la historia natural de la infección del adulto $10 \%$ de los portadores puede avanzar a una hepatitis crónica.

Inmunidad adquirida: presencia de anticuerpos anti-HBsAg, lo que se asimila a inmunidad protectora adquirida por infección o por vacuna.

Inactividad replicativa: se refiere a la presencia de anti-HBe.

\section{RESULTADOS}

\section{Magnitud de infección por VHB}

Estudios nacionales. En la Tabla 1 se observa que una gran parte de los estudios publicados en el medio nacional son de la década de 1980-89. Se caracterizan por ser estudios descriptivos y de prevalencia en grupos de riesgo con muestras que no son representativas de la población.

Seroprevalencia de portación. En general los diversos estudios coinciden que la seroprevalencia 
Tabla 1. Resultados de búsqueda bibliográfica

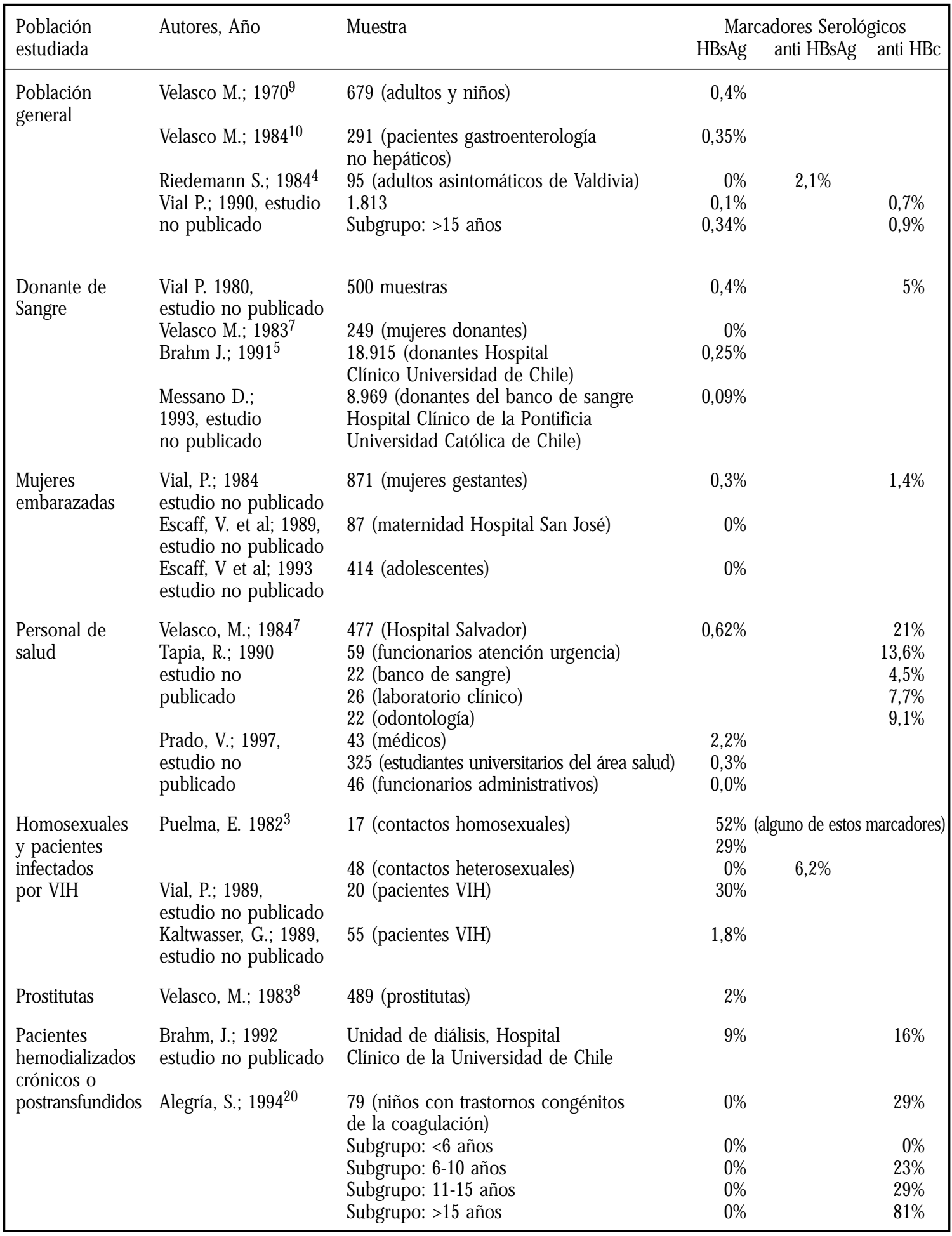


en población supuestamente sana, debiera ser alrededor de 0,3\%4,7,9,14,17,19. Adicionalmente a los datos reportados, en este grupo los de mayor riesgo son los adultos jóvenes (25-35 años) y más frecuente en la población masculina ${ }^{14,17}$. En mujeres embarazadas la prevalencia es de $0,2 \% 19$ (Escaff M. 1989 y 1993 estudios no publicados).

En los grupos de riesgos se observa que la seroprevalencia de portación, es decir portadores del HBsAg positivos, es: a) Donantes de sangre: 00,25\%5,8,19 (Messano. 1993 estudio no publicado). b) Personal de salud: es de $0,7 \% 7,10$ pero varía desde $0 \%$ en funcionarios administrativos a 2,2\% (Prado V. 1997 estudio no publicado). c) Población homosexual se estima que $52 \%$ tendría algún marcador positivo para hepatitis B y $29 \%$ sería positivo a $\mathrm{HbsAg}^{3}$. d) Pacientes VIH positivo varían entre 1,8\% y $30 \%$ de positividad (Vial P. 1989; Kaltwasser G. 1989 estudios no publicados). e) Prevalencia en trabajadores sexuales es de $2 \%{ }^{8}$. f) Pacientes hemodializados crónicos varía entre $0 \%$ y $9 \% 19,20$.

El último estudio disponible con base poblacional, corresponde a la Encuesta Nacional de Salud, $2003^{21}$. La edad de los sujetos sometidos al estudio de prevalencia de portación fluctuó entre 17 y 44 años de edad. La seroprevalencia total fue estimada en 0\% (I.C 95\%: 0,0-0,29).

Seroprevalencia de infección. Los estudios de seroprevalencia realizados a finales de la década de 1990-99 permiten concluir una baja seroprevalencia de infección de hepatitis $B^{17,22,23}$, sin embargo ésta aumenta con la edad; la prevalencia de anticuerpos anticore en el grupo de 16 a 20 años fue de $1 \%$ y entre 31 y 40 años fue de $4 \% 23$. La seroprevalencia global de infección fue estimada en 0,6\%.

La Tabla 2 resume tres estudios publicados y muestra los resultados por grupos de edad, pudiendo comparar los resultados de Chile con los de otros países.

Estudios no publicados. Corresponde a un estudio realizado en el Servicio de Salud Oriente durante el año 2000. El grupo de estudio fue una muestra representativa de embarazadas y consultantes de ETS de ese Servicio (Valenzuela MT, Silva MA, Escobar P, Chomalí M, 2000, estudio no publicado). Los resultados se muestran en la Tabla 3. La

Tabla 2. Epidemiología de la H B en América Latina estudios de prevalencia actuales

\begin{tabular}{|lrlllrr|}
\hline País & $\mathrm{N}^{\circ}$ & \multicolumn{5}{c|}{ Anti-HBs/C- Edad (años) } \\
& & $<$ & $1-5$ & $6-10$ & $11-15$ & $15-17 / 20$ \\
\hline México & 5.212 & 0 & 0,8 & 0,8 & 0,8 & 1,2 \\
Brasil & 4.708 & 7 & 3,8 & 8 & 4,8 & 5,6 \\
Venezuela & 469 & 0 & 1,7 & 4,1 & 0 & 4,6 \\
Rep. Dominicana & 473 & 0 & 9,9 & 6,6 & 10,9 & 26,2 \\
Chile & 496 & 0 & 0 & 0,0 & 0 & 1,1 \\
Argentina & 1.454 & 3,1 & 2,7 & 2,7 & 1 & 0,7 \\
\hline
\end{tabular}

Ref: Focaccia R et al. Braz J Inf Dis 1998. Silveira TR et al. Rev Panam Salud Pública 1999. Tanaka J et al. Vaccine 2000

Tabla 3. Seroprevalencia de infección y de portación por VH B en embarazadas y ET S S.S.M. 0 riente 2000

\begin{tabular}{|lrrrrr|}
\hline & Total & N & $\%$ & N & Anti-core + \\
\hline Embarazada & 508 & 1 & 0,2 & 13 & 2,6 \\
ETS & 63 & 1 & 1,6 & 3 & 4,8 \\
Total & 571 & 2 & 0,4 & 16 & 2,8 \\
\hline
\end{tabular}


seroprevalencia de portación general fue de $0,4 \%$, existiendo grandes diferencias entre ambos grupos, desde $0,2 \%$ en embarazadas a $1,6 \%$ en consultantes ETS. La prevalencia de infección en ambos grupos fue de 2,8\%, la que fluctuó entre $2,6 \%$ y $4,8 \%$, respectivamente.

Opinión de expertos. El porcentaje de casos de hepatitis B que atiende al año un hepatólogo en general es $2 \%$ del total de casos de hepatitis, aunque ellos reconocen generalmente no notificar. El 90\% presenta una hepatitis aguda con recuperación total y 8\%-10\% quedan como portadores del VHB, es decir HBsAg positivo. De este grupo 12\%-20\% evoluciona a hepatitis crónica con cirrosis en 5 años. Tan sólo $55 \%$ a $80 \%$ sobrevive a cinco años, constituye el grupo de pacientes con el más alto riesgo de desarrollar un cáncer hepatocelular. La hepatitis crónica se caracteriza por la presencia de alta replicación viral e inflamación necrótica del hígado.

La hepatitis crónica puede tener dos formas de presentación:

1. Con presencia de HBeAg, que es la forma en la cual existe la mayor replicación viral, con niveles de aminotransferasa altos, ya sea a permanencia o en forma intermitente. En 5\% y 10\% de estos casos por año puede desaparecer el HBeAg y desarrollar anticuerpos anti-HBeAg.

2. Con generación de anticuerpos anti-HBeAg. La hepatitis crónica rara vez remite en forma espontánea, con frecuencia avanza hacia cirrosis hepática y con un alto riesgo de desarrollar cáncer hepatocelular.

Debido al alto costo del tratamiento, los casos del sistema público no acceden a un manejo terapéutico para VHB. Los tratamientos más habituales son el uso de interferón, lamivudina y adefovir, pero actualmente no cuentan con un esquema consensuado sobre cuál es la mejor opción ${ }^{15,24}$, ni tampoco se cuenta con cobertura financiera para acceder a ella.

Casos notificados por E.N.O (ex RMC-14). Las tasas de prevalencia desde 1991 a 2004 tienen una tendencia al ascenso leve pero persistente en el tiempo, desde 1 x 100.000 a 1,8 x 100.000 habitantes ${ }^{25}$. La distribución por regiones de Chile no es uniforme, siendo las áreas de mayor riesgo la I y la III regiones, donde el riesgo expresado en tasas es superior a 3 por 100.000 habitantes, mientras que en la XI y XII regiones no se registran casos para 2004 (Tabla 4).

Laboratorios y bancos de sangre. En la Tabla 5, se presentan los valores de prevalencia desde 1999 a 2004. Se debe considerar que los números promedio de casos mensuales provenientes de donantes y no donantes no corresponden al total de casos que se notifica en nuestro país. El número de laboratorios y banco de sangre que realizan la

Tabla 4. Incidencia de hepatitis B por Servicio de Salud C hile, 2003-2004

\begin{tabular}{|lcc|}
\hline Servicios de Salud & Tasa 2003 & Tasa 2004 \\
\hline Arica & 0 & 1,05 \\
Iquique & 3,35 & 5,02 \\
Antofagasta & 1,62 & 2,02 \\
Atacama & 2,36 & 3,93 \\
Coquimbo & 0,00 & 0,99 \\
Valparaíso-San Antonio & 0,91 & 2,73 \\
Viña del Mar-Quillota & 1,37 & 0,68 \\
Aconcagua & 0,89 & 4,47 \\
Metropolitano Norte & 2,35 & 3,23 \\
Metropolitano Occidente & 0,55 & 0,83 \\
Metropolitano Central & 3,44 & 2,29 \\
Metropolitano Oriente & 4,30 & 4,84 \\
Metropolitano Sur & 2,30 & 3,26 \\
Metropolitano Sur Oriente & 0,61 & 0,77 \\
O’Higgins & 0,77 & 0,00 \\
Maule & 0,66 & 0,44 \\
Nuble & 0,00 & 0,00 \\
Concepción & 1,77 & 2,84 \\
Arauco & 0,00 & 0,00 \\
Talcahuano & 0,00 & 2,29 \\
Bío-Bío & 0,00 & 0,00 \\
Araucanía Norte & 0,00 & 0,99 \\
Araucanía Sur & 0,00 & 0,60 \\
Valdivia & 0,56 & 1,12 \\
Osorno & 0,90 & 0,00 \\
Llanchipal & 0,81 & 1,62 \\
Aysén & 4,37 & 0,00 \\
Magallanes & 0,00 & 0,00 \\
Total & 1,4 & 1,8 \\
\hline
\end{tabular}

Fuente de información: Estadísticas-MINSAL-Chile. 
Tabla 5. Prevalencia de positividad del H BsAg en donantes y no donantes informada por los laboratorios participantes del Programa de Evaluación Externa de la C alidad, C hile 1999-2004

\begin{tabular}{|lcccccc|}
\hline Año & $\begin{array}{c}\text { № donantes } \\
\text { promedio mes }\end{array}$ & $\begin{array}{c}\text { № donantes } \\
\text { positivos } \\
\text { promedio mes }\end{array}$ & \% positividad & $\begin{array}{c}\text { № No donantes } \\
\text { promedio mes }\end{array}$ & $\begin{array}{c}\text { № No donantes } \\
\text { positivos } \\
\text { promedio mes }\end{array}$ & \% positividad \\
\hline 1999 & 20.696 & 36,4 & 0,2 & 8.227 & 62,8 & 0,8 \\
2000 & 15.792 & 28,4 & 0,2 & 3.972 & 56,9 & 1,4 \\
2001 & 16.667 & 21,4 & 0,1 & 5.093 & 86,5 & 1,7 \\
2002 & 17.339 & 29,2 & 0,2 & 5.682 & 83,2 & 1,5 \\
2003 & 14.177 & 29,2 & 0,2 & 6.075 & 94,9 & 1,6 \\
2004 & 17.453 & 29,4 & 0,2 & 6.595 & 86,0 & 1,3 \\
\hline
\end{tabular}

Fuente de información: Laboratorio de referencia HB, Instituto de Salud Pública de Chile.

determinación de HBsAg varían en los años, siendo 134 en 2004 hasta 147 en 2002. Si se estima un valor promedio de prevalencia de portación entre 1999 y 2004, éste sería de $0,2 \%$ en los donantes y $1,3 \%$ en los no donantes.

\section{Discusión}

Chile puede considerarse como un país de baja endemia, ya sea a nivel mundial y en el contexto de países de Latinoamérica ${ }^{15,17,23}$.

$\mathrm{Si}$ la portación de hepatitis $\mathrm{B}$, utilizando la información más consistente, es menor a $0,3 \%$ en adultos $^{4,9,10}$ en una población de 11.226 .309 mayores de 15 años en Chile ${ }^{25}$, habría alrededor de 33.679 portadores de la hepatitis B capaces de mantener la transmisión de la infección.

Esta infección crónica persistente puede tener tres patrones histológicos en la biopsia hepática: 1. hepatitis crónica persistente; 2 . hepatitis crónica activa; y 3. cirrosis.

$\mathrm{Si}$ asumimos que 8\% de los 33.679 portadores avanzarían a infección crónica, tendríamos en esta cohorte una carga de 2.694 enfermos para los próximos años. Si de ellos $12 \%$ avanzara a cáncer hepatocelular primario, en los próximos 20-25 años tendríamos 323 casos a partir de estas cohortes.

La única forma de confirmar esta hipótesis seńa a través de: a) Un sistema de vigilancia epidemiológica activa de hepatitis B en Chile a partir del laboratorio, con una buena estandarización de definición de caso a investigar, los métodos de pesquisa, de confirmación y de notificación de los casos activos y portadores crónicos del virus. b) Además Chile debiera disponer de un buen sistema de seguimiento de los casos activos por lo menos hasta un año después del diagnóstico, con el objetivo de saber si el caso quedó como portador crónico o no. c) Un buen sistema de seguimiento de los portadores crónicos del virus, con un programa de educación y consejería incorporado en las enfermedades de transmisión sexual, a objeto de evitar o disminuir la transmisión del virus a los contactos íntimos (que viven en el mismo hogar) y contactos sexuales.

$\mathrm{Si}$ bien se insiste en la baja prevalencia del problema en Chile, éste toma relevancia por las siguientes razones:

1. El único estudio con base poblacional que aporta datos sobre portación del VHB es el recientemente realizado en 2003. En este estudio se observa una prevalencia de portación de 0\% (IC 95\%: 0,0-0,29\%), sin embargo es sólo en población joven, que no incluyó a edades superiores a 44 años. Otros estudios realizados en la década de 1980-89 presentan prevalencias de $0,3 \%$, las cuales aumentan según grupos de riesgo.

2. Los lugares del país que concentran el mayor riesgo de hepatitis B son la I y la III regiones.

3. Las cohortes antes de 1982 estuvieron expuestas a la transmisión del virus vía transfusiones, pues antes de esa fecha no había control de calidad de la sangre de donantes en los bancos de sangre. Por lo tanto, sin duda, si se hiciera un estudio de 
prevalencia de portación en los mayores de 40 años, nos encontraríamos con prevalencias mayores que los promedios nacionales.

4. Los pacientes crónicos hoy no disponen de tratamiento en el sistema público de salud al que accede $71,7 \%$ de la población para el año 2003, y más de 79,7\% de la población sobre 60 años de edad 26 .

5. Los tratamientos son de un alto costo y de duración variable, que puede fluctuar de 4-6 meses hasta 1-2 años ${ }^{24}$. De acuerdo a la clasificación de la población en Chile, accederían al tratamiento el segmento $\mathrm{A}, \mathrm{B}$ y $\mathrm{C} 1$ (información del Banco Central). A este segmento de población pertenece tan sólo $10 \%$ de los habitantes de Chile.

Durante la década de 1980-89 y principios de la década 1990-99 se realizaron muchos estudios sobre VHB. Estos estudios incorporaron muestras de población o de población en riesgo no representativas ni de la población general ni de los grupos de riesgo, limitando la validez interna y externa de los resultados de ellos. Por lo tanto, se debe continuar en estas líneas de investigación para lograr una mayor precisión de la realidad y poder estimar el verdadero efecto y magnitud de esta enfermedad en Chile.

En conclusión, lo más relevante de este estudio ha sido mostrar que en Chile con los datos

\section{REFERENCIAS}

1. MAHONEY FJ. Update on diagnosis, management and prevention of hepatitis B virus infection. Clin Microbiol Rev 1999; 12: 351-66.

2. Jirón MI, Armas-Merino R, Soto JR, Vargas-Tank L, Lово G, Pacheco J. Marcadores séricos del virus B de la hepatitis en hepatitis crónica activa. Rev Méd Chile 1983; 111: 463-5.

3. Puelma E, Velasco M. Marcadores de los virus de la hepatitis en un grupo de homosexuales. Rev Méd Chile 1982; 110: 1176-8.

4. Riedemann S, Hochstein-Mintzel V, Reinhardt G. Prevalencia de hepatitis A y B en la población de Valdivia: estudio seroepidemiológico. Rev Méd Chile 1984; 112: 672-4.

5. Brahm J, Hurtado C, Latorre R, Velasco M, Larron- disponibles no se puede tener un real conocimiento de la magnitud de la enfermedad ni las implicancias de ella en complicaciones tales como cirrosis y cáncer hepatocelular primario. Además, los casos notificados no necesariamente corresponden a los casos que, ya sea a través de bancos de sangre o laboratorios clínicos se están diagnosticando, lo que también implica que existe una falta de motivación de los especialistas para notificar.

A pesar que la prevalencia de infección es baja, entre $0 \%$ y $0,3 \%$, la historia natural de la infección por el virus hepatitis B es muy distinta a la historia de la gran mayoría de las enfermedades transmisibles. Éstas se caracterizan por tener un cuadro clínico definido, una respuesta inmune que en general le confiere inmunidad al huésped a largo plazo, en cambio la infección por el virus hepatitis B no se resuelve en la etapa aguda, por el contrario, existe un porcentaje de infectados que tiene la posibilidad de continuar como portadores con riesgo de avanzar a complicaciones $^{5,14-16,27,28}$.

Todos estos puntos han servido de argumento para comenzar a desarrollar en Chile la vigilancia epidemiológica de hepatitis B y C a partir del laboratorio. Se espera contar con el respaldo de la autoridad sanitaria, de la comunidad científica y de los niveles operativos en esta meta para establecer la vigilancia epidemiológica.

DO M, ORREGo E. Infección con el virus de la hepatitis B en donantes de sangre en Chile. Estudio prospectivo (1988-1990). Rev Méd Chile 1991; 119: 354.

6. Brahm J, Hurtado C, Velasco M. Hepatitis aguda por virus B en Chile: características clínicas y evolución. Rev Méd Chile 1990; 118: 264-8.

7. Velasco M, Brham J, Borgono JM, Concha E, Veit $\mathrm{O}$, ZaVALA C. Antígeno de superficie de la hepatitis B (HBsAg) y anticuerpo anti-HBs en consultantes ambulatorios y en personal de hospital. Rev Méd Chile 1984; 112: 994-7.

8. Velasco M, De ia Fuente C. Estudio del antígeno de superficie de la hepatitis B en 489 prostitutas de Santiago. Rev Méd Chile 1983; 111: 461-2.

9. Velasco M, Katz R. Antígeno australiano en muestras de población chilena y en diversos 
cuadros patológicos. Rev Méd Chile 1970; 98: 1-5.

10. Velasco M, Katz R, Puelma E, Brahm J, González M, Donoso S. Estudio prospectivo de portadores crónicos asintomáticos del antígeno de superficie de la hepatitis B. Rev Méd Chile 1984; 112: 115-20.

11. Velasco M, Sepúlveda C. HTLV-III, virus hepatitis B y CMV en homosexuales chilenos. Rev Méd Chile 1985; 113: 587-9.

12. Velasco M, Sorense R, Daiber A, Carmona A, Katz R. Primary carcinoma of the liver associated with Australia antigen. Lancet 1971; 1: 1183-4.

13. TREPO C. [Hepatitis virus C: from discovery to applications in public health]. Rev Prat 1990; 40: 1631-9.

14. Zunino E. Epidemiología de la hepatitis B en Chile y esquemas de vacunación en Latinoamérica. Rev Chil Infectol 2002; 19: 140-55.

15. Grupo GME Galcia. Hepatitis B. Guías Clínicas, 2004; 4: 1-9. Disponible en: www. fisterra.com [Consultado el 25 de febrero de 2006].

16. De Franchis R, Hadengue A, Lau G, Lavanchy D, Lok A, McLnTyre N. EASL International Consensus Conference on Hepatitis B. 13-14 September, 2002 Geneva, Switzerland. Consensus statement (long version). J Hepatol 2003; 39 Suppl 1: S3-25.

17. Silveira TR, Da Fonseca JC, Rivera L, Fay OH, Tapia R, SANTOS JI ET AL. Hepatitis B seroprevalence in Latin America. Rev Panam Salud Pública 1999; 6: 378-83.

18. MuÑoz G. Diagnóstico serológico y virológico de la hepatitis C y B: Aspectos prácticos. Gastr Latinoam 2006; 17: 249-52.

19. Cofré J. Vacunas anti hepatitis B: Su aplicación en Chile. Rev Chil Infectol 1999; 16: 50-5.

20. Alegría S, Morales M, Vildósola J, Hurtado C, BraHm J. Infección con los virus de la hepatitis B y
C en niños con trastornos congénitos de la coagulación. Rev Méd Chile 1994; 122: 638-42.

21. MINSAL. Resultado I Encuesta Nacional de Salud, Chile 2003. Gobierno de Chile, Ministerio de Salud. Disponible en: www. minsal .cl [Consultado el 10 de marzo 2006].

22. Focaccia R, Da Conceicao OJ, Sette H Jr, Sabino E, BASSIT L, NITRIN DR et al. Estimated prevalence of viral hepatitis in the general population of the Municipality of Sao Paulo, measured by a serologic survey of a stratified, randomized and residence-based population. Braz J Infect Dis 1998; 2: 269-84.

23. TANAKA J. Hepatitis B epidemiology in Latin America. Vaccine 2000; 18 Suppl 1: S17-9.

24. Brahm J. Hepatitis crónica. En: Diagnóstico y Tratamiento de las Enfermedades Digestivas, Sociedad Chilena de Gastroenterología, Editor. 2002.

25. MINSAL. Departamento de Estadísticas e Información en Salud, 2006. Disponible en: http: // deis.minsal.cl/index.asp (Consultado el 2 de abril 2006).

26. Encuesta Casen 2003. Gobierno de Chile. Ministerio de Planificación y Cooperación. Disponible en: http: //www.mideplan.cl/casen [Consultado el 15 de marzo 2006].

27. Sculard GH, Poшard RB, Smith JL, Sacks SL, Gregory PB, RoBinson WS. Antiviral treatment of chronic hepatitis B virus infection. I. Changes in viral markers with interferon combined with adenine arabinoside. J Infect Dis 1981; 143: 772-83.

28. Sampliner RE, Hamlton FA, Iseri OA, TABor E, BorтnotT $\mathrm{J}$. The liver histology and frequency of clearance of the hepatitis B surface antigen (HBsAg) in chronic carriers. Am J Med Sci 1979; 277: 17-22. 